\title{
Two Degree of Freedom Frequency Domain Surface Location Error Prediction
}

\author{
Kadir Kiran ${ }^{1,2}$, Mark Rubeo ${ }^{2}$, Mehmet Cengiz Kayacan ${ }^{1}$, Tony Schmitz ${ }^{2}$ \\ ${ }^{1}$ Department of Mechanical Engineering, Suleyman Demirel University, Isparta, Turkey \\ ${ }^{2}$ Department of Mechanical Engineering and Engineering Science, University of North \\ Carolina at Charlotte, Charlotte, NC, USA
}

\begin{abstract}
This paper presents a two degree of freedom (DOF) closed-form frequency domain solution for surface location error prediction, including both the tool and workpiece flexibility. The cycloidal tool path is incorporated in the solution and the machined surface geometry is described by combining the tool path with the tool and workpiece displacements in two directions. For prediction validation, a two DOF flexure stage with tunable dynamics was constructed and milling tests were performed over a range of spindle speeds. Time domain simulations were also completed and a comparison between the closed-form frequency domain surface location error predictions, time domain predictions, and experimental results is provided.
\end{abstract}

\section{Keywords}

Milling; forced vibration; surface location error; stability

\section{Introduction}

Instability, or chatter, is a well-known limitation to high productivity for milling operations. Chatter is a self-excited vibration that occurs due to the closed-loop feedback mechanism in machining processes. It is possible to avoid chatter vibrations by appropriate selection of the process parameters (specifically, stable combinations of axial depth of cut and spindle speed for a selected radial depth) using stability maps that can be constructed using analytical and numerical methods [1-8]. However, even if stable cutting conditions are selected, surface location error, or workpiece geometric inaccuracies due to forced vibrations, can still limit productivity.

During stable cutting, the periodic cutting force that exists due to the inherent interrupted cutting conditions in milling lead to forced vibrations for the tool and workpiece [9]. The cutting force, which depends on the machining parameters and tool-work material combination, causes the tool and workpiece to deflect. This time-dependent displacement depends on both the tool and workpiece frequency response functions (FRFs) and the 
excitation frequency (spindle speed) [10-11]. Due to the phasing between these vibrations and the time at which the final surface is generated, the workpiece may be undercut (less material removed than commanded) or overcut (more material removed than commanded). This difference between the commanded and actual work dimensions is referred to as surface location error.

Surface location error (SLE) has been studied previously. For example, Schmitz and Ziegert [11] explored the influence of spindle speed and the tool-holder-spindle-machine assembly FRF on SLE using time domain simulation. Shirase and Altintas [12] carried out SLE prediction for variable pitch helical end mills. They observed that variable pitch cutters alter both SLE and stability behavior. Closed-form frequency domain and harmonic balance SLE predictions were presented by Schmitz and Mann [10]. The concept was to solve the forced vibration problem in the frequency domain and then convert back to the time domain for the final SLE prediction. In 2008, Mann et al. [13] again used the harmonic balance solution to predict SLE. They included the influence of cutting tool helix angle on cutting force by integration. Temporal finite element analysis was also employed to predict stability and surface location error at the same time. Schmitz et al. [14] considered the effect of cutter teeth runout on SLE in milling. They provided a comprehensive time domain simulation, which computed the cutting force components and tool and workpieces vibrations by considering the contributions of the tool and workpiece displacements to the instantaneous chip thickness. The cycloidal motion of the tool was incorporated. Zapata and Schmitz [15] presented a new analytical "super diagram" by combining SLE and stability limits in a single process map. SLE variation along the tool axial due to helix angle was studied by Bachrathy et al. [16]. Kiss et al. provided SLE prediction for a rigid workpiece and flexible tool having multiple degrees of freedom [17]. Additional studies have also been conducted using various analytical and numerical methods to estimate the SLE in milling operations [18-23]. However, the majority of these prior efforts have assumed that either the tool or workpiece is flexible, but not both.

In this paper, the contribution of both tool and workpiece flexibility to SLE in milling is considered in two directions (i.e., the feed and perpendicular directions within the plane of the cut). The machined surface geometry is defined by combining the cycloidal tool path with both the tool and workpiece displacements. These displacements are calculated using the closed-form frequency domain solution developed by Schmitz and Mann [10], but in two directions. The SLE and average surface roughness are computed based on the predicted machined surface geometry. The paper is organized as follows. Section 2 summarizes the 
closed-form frequency domain solution for one direction. Section 3 presents the Fourier representation of cutting force components. Section 4 describes the SLE and average surface roughness prediction algorithm. Section 5 presents the experimental setup used to validate the SLE predictions. Section 6 provides a comparison between the frequency domain, time domain, and experimental results. Section 7 discusses the influence of spindle speed on machined surface geometry. Section 8 concludes the paper.

\section{Single direction frequency domain solution}

As stated, forced vibrations during stable cutting cause SLE (i.e., workpiece geometry error). The workpiece may be undercut or overcut depending on the cutting conditions and toolworkpiece flexibility. Figure 1 demonstrates the undercut case, where less material is removed than commanded, for down milling.

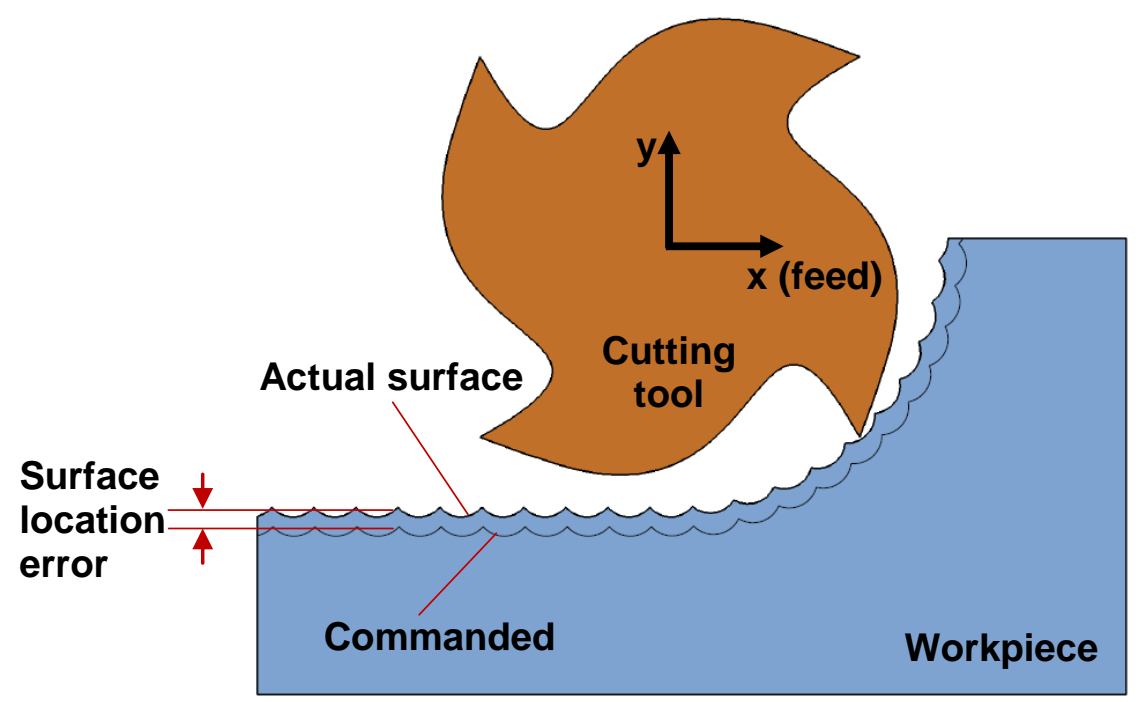

Figure 1. Undercut case for down milling.

The closed-form frequency domain SLE approach [10] is based on a solution of the forced vibration problem in the frequency domain. The procedure consists of three basic steps. First, the y-direction cutting force, $F_{y}(\omega)$, is described in the frequency domain using a Fourier series. Second, the y-direction displacement, $Y(\omega)$, is computed in the frequency domain by multiplying $F_{y}(\omega)$ with the y-direction tool point FRF, $\mathrm{Y}(\omega) / \mathrm{F}_{\mathrm{y}}(\omega)$. Third, the inverse Fourier transform of $Y(\omega)=\mathrm{Y}(\omega) / \mathrm{F}_{\mathrm{y}}(\omega) \cdot \mathrm{F}_{\mathrm{y}}(\omega)$ is computed to obtain the $\mathrm{y}$ direction displacement in the time domain, $y(\mathrm{t})$. Finally, $y(t)$ is sampled at the cut entry for up milling or exit for down milling to define the SLE. In [10], the authors only considered the 
$y$-direction vibrations to predict SLE. In this work, the $\mathrm{x}$-direction vibrations are also calculated and included in the SLE predictions (Section 4).

\section{Fourier force model}

The cutting force components must be expressed in the frequency domain to compute SLE using the proposed frequency domain solution. The cutting force components in milling can be expressed as shown in Eq. 1 and Fig. 2 [9].

$$
\begin{aligned}
& F_{t}(\phi)=\mathrm{k}_{\mathrm{t}} \mathrm{bh}(\phi)+\mathrm{k}_{\mathrm{te}} \mathrm{b} \\
& F_{n}(\phi)=\mathrm{k}_{n} \mathrm{bh}(\phi)+\mathrm{k}_{\mathrm{ne}} \mathrm{b}
\end{aligned}
$$

In Eq. $1, F_{t}$ and $F_{n}$ are the tangential and normal direction force components, $b$ is the axial depth of cut, $h$ is chip thickness, $\phi$ is tooth angle, and $k_{t}, k_{n}, k_{t e}$ and $k_{n e}$ are the tangential, normal, tangential edge, and normal edge cutting force coefficients.

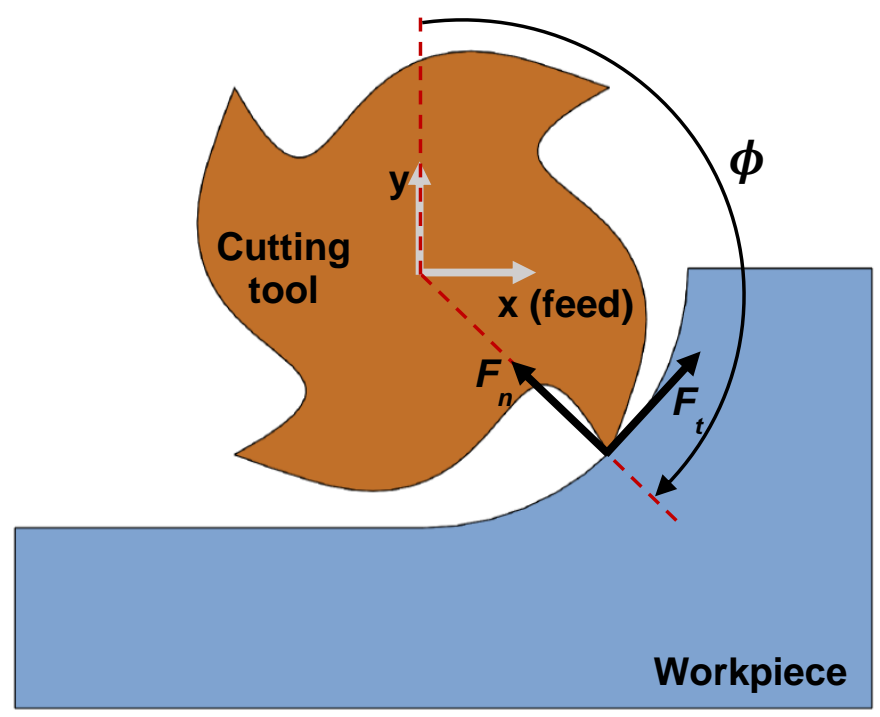

Figure 2. Cutting force components for down milling.

The force components in Eq. 1 rotate with the cutting tool. In order to describe the fixed $x$ and $y$-direction force components, the tangential and normal forces are projected into the $x$ and $y$-directions using the cutter angle, $\phi$.

$$
\begin{aligned}
& F_{x}=F_{t} \cos (\phi)+F_{n} \sin (\phi) \\
& F_{y}=F_{t} \sin (\phi)-F_{n} \cos (\phi)
\end{aligned}
$$


The instantaneous chip thickness in Eq. 1 can be written as $h(\phi)=f_{t} \sin (\phi)$, where $f_{t}$ is the feed per tooth. The $x$ and $y$-direction cutting force components are finally written as:

$$
\begin{gathered}
F_{x}(\phi)=-b\left[\begin{array}{c}
\frac{-k_{t} f_{t}}{2} \sum_{i=1}^{N_{t}} g\left(\phi_{\mathrm{i}}\right) \sin \left(2 \phi_{\mathrm{i}}\right)-\frac{k_{n} f_{t}}{2} \sum_{i=1}^{N_{t}} g\left(\phi_{\mathrm{i}}\right)\left(1-\cos \left(2 \phi_{\mathrm{i}}\right)\right)- \\
k_{t e} \sum_{i=1}^{N_{t}} g\left(\phi_{\mathrm{i}}\right) \cos \left(\phi_{\mathrm{i}}\right)-k_{n e} \sum_{i=1}^{N_{t}} g\left(\phi_{\mathrm{i}}\right) \sin \left(\phi_{\mathrm{i}}\right)
\end{array}\right] \\
F_{y}(\phi)=-b\left[\begin{array}{c}
\frac{-k_{t} f_{t}}{2} \sum_{i=1}^{N_{t}} g\left(\phi_{\mathrm{i}}\right)\left(1-\cos \left(2 \phi_{\mathrm{i}}\right)\right)+\frac{k_{n} f_{t}}{2} \sum_{i=1}^{N_{t}} g\left(\phi_{\mathrm{i}}\right) \sin \left(2 \phi_{\mathrm{i}}\right)- \\
k_{t e} \sum_{i=1}^{N_{t}} g\left(\phi_{\mathrm{i}}\right) \sin \left(\phi_{\mathrm{i}}\right)+k_{n e} \sum_{i=1}^{N_{t}} g\left(\phi_{\mathrm{i}}\right) \cos \left(\phi_{\mathrm{i}}\right)
\end{array}\right]
\end{gathered}
$$

where $N_{t}$ is number of teeth and $g\left(\phi_{\mathrm{i}}\right)$ is switching function that defines if the tooth is in cut $\left(g\left(\phi_{\mathrm{i}}\right)=1\right)$ or not $\left(g\left(\phi_{\mathrm{i}}\right)=0\right)$. All teeth engaged in the cut are taken into consideration using the summations in Eqs. 3 and 4 ( $i$ is the tooth number). The angle of each tooth can be computed at any instant in time using the expression: $\phi_{i}=\omega t+\left(2 \pi / N_{t}\right)(i-1)(\mathrm{rad})$, where $\omega$ is the spindle rotating frequency (in $\mathrm{rad} / \mathrm{s}$ ).

Since the cutting force components are periodic, they can be represented by a Fourier series. As an example, the $y$-direction force component can be expressed as shown in Eq. 5 .

$$
F_{y}(\phi)=\sum_{i=1}^{N_{t}}\left(\mathrm{a}_{0}+\sum_{n=1}^{\infty}\left(\mathrm{a}_{n} \cos \left(n \phi_{i}\right)+b_{n} \sin \left(n \phi_{i}\right)\right)\right)
$$

The Fourier coefficients are $a_{0}, a_{n}$, and $b_{n}$. The $a_{0}$ term is calculated using Eq. 6 . The integral for a full revolution of the selected tooth may be divided into three parts using $\phi_{1}$, the cut entry angle in down milling or exit angle in up milling. For the down milling case, the first integral is zero and the middle integral in Eq. 6 is non-zero due to the switching function $\left(g\left(\phi_{\mathrm{i}}\right)=1\right.$ when the cutter angle is between the start and entry angles for the selected radial depth of cut, otherwise $g\left(\phi_{\mathrm{i}}\right)=0$ ). The final integral is always zero because a tooth is never engaged for this range of tooth angles. Integration of the middle term yields Eq. 7 with cut entry to exit limits from $\phi_{1}$ to $\pi$. In a similar manner, only the first integral is non-zero for up milling [9]. 


$$
\begin{gathered}
a_{0}=\frac{1}{2 \pi} \int_{0}^{2 \pi} F_{y}(\phi) d \phi=\frac{1}{2 \pi}\left(\int_{0}^{\phi_{1}} F_{y}(\phi) d \phi+\int_{\phi_{1}}^{\pi} F_{y}(\phi) d \phi+\int_{\pi}^{2 \pi} F_{y}(\phi) d \phi\right) \\
a_{0}=-\frac{b N_{t}}{2 \pi}\left[-\frac{k_{t} f_{t} \phi}{2}+\frac{k_{t} f_{t}}{4} \sin 2 \phi-\frac{k_{n} f_{t}}{4} \cos 2 \phi+k_{t e} \cos \phi+k_{n e} \sin \phi\right]_{\phi_{1}}^{\pi}
\end{gathered}
$$

The $a_{n}$ and $b_{n}$ coefficients are computed using Eqs. 8 and 9, respectively. The same solution procedure using $\phi_{1}$ is applied here and the relevant integrals are calculated to obtain the coefficients for desired number, $n$, of terms.

$$
\begin{aligned}
& a_{n}=\frac{1}{\pi} \int_{0}^{2 \pi} F_{y}(\phi) \cos (n \phi) d \phi \\
& b_{n}=\frac{1}{\pi} \int_{0}^{2 \pi} F_{y}(\phi) \sin (n \phi) d \phi
\end{aligned}
$$

In order to incorporate the effect of the helix angle, $\gamma$, for the cutter teeth on the cutting force components, the cutting tool is divided into small axial segments along the tool axis (zdirection). It is assumed that each segment has a zero helix angle and the angle between the $A$ segments is $\chi=\frac{2 d b \tan (\gamma)}{d} \mathrm{rad}$, where $d b$ is segment length and $d$ is the cutting tool diameter. In this case, the Fourier series for the $y$-direction cutting force is written as $F_{y}(\phi)=\sum_{j=1}^{A} \sum_{i=1}^{N_{t}}\left(\mathrm{a}_{0}+\sum_{n=1}^{\infty}\left(\mathrm{a}_{n} \cos \left(n \phi_{i}\right)+b_{n} \sin \left(n \phi_{i}\right)\right)\right)$, where $\phi_{i}=\omega t+\frac{2 \pi}{N_{t}}(i-1)-\chi(j-1)$. The $\mathrm{x}$-direction force component is defined using the same Fourier series procedure. Error! Reference source not found. displays a comparison between the Fourier series representation of force components for $n=60$ and the forces obtained using time domain simulation. The down milling cutting parameters are: $\omega=466.66 \pi \mathrm{rad} / \mathrm{s}$ (i.e., the spindle speed, $\Omega$, is $14000 \mathrm{rpm}), f_{t}=0.1 \mathrm{~mm} /$ tooth, $\gamma=0^{\circ}, N_{t}=4, b=6 \mathrm{~mm}$, the radial depth of cut , $a$, is $1 \mathrm{~mm}, k_{t}=852.6 \times 10^{6} \mathrm{~N} / \mathrm{m}^{2}, k_{n}=322.17 \times 10^{6} \mathrm{~N} / \mathrm{m}^{2}, k_{t e}=k_{n e}=0 \mathrm{~N} / \mathrm{m}$. 


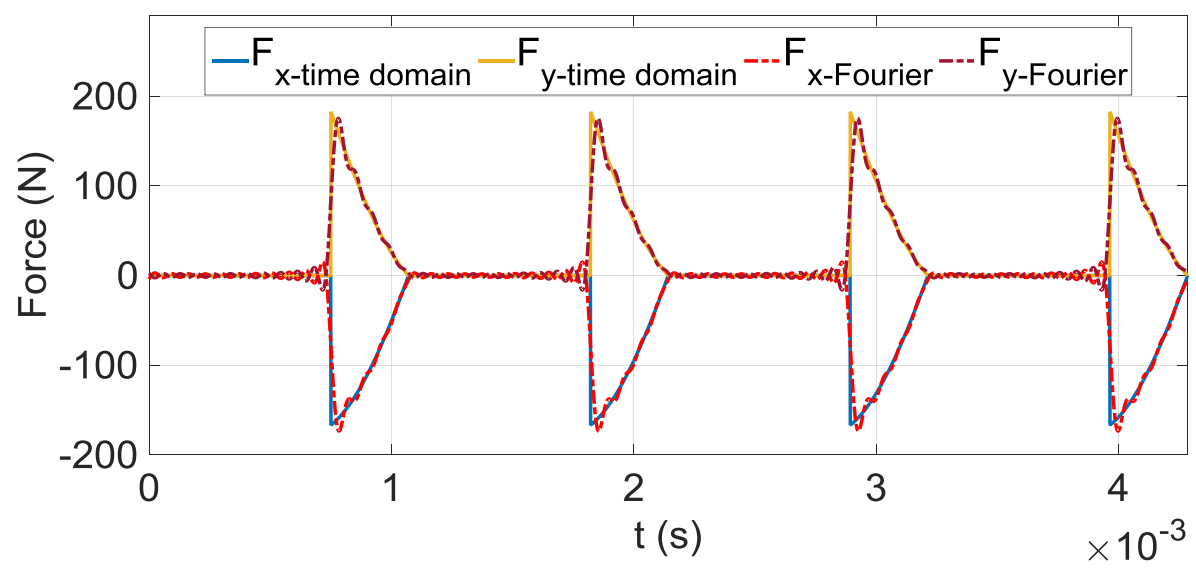

Figure 3. Comparison of cutting force components calculated using time domain simulation (solid lines) and Fourier series for $n=60$ (dash-dot lines).

As seen in Error! Reference source not found., the Fourier series representation adds minor "ringing" at the discontinuities in the cutting forces because the piecewise continuous cutting force components are represented with a continuous signal (Fourier series). This is Gibbs phenomenon.

\section{The algorithm}

The SLE algorithm is similar to that described in Section 2. However, in addition to the steps previously defined: 1) the x-direction displacements are included; 2) both the tool and workpiece FRFs are used to calculate the $x$ and y-direction displacements; and 3) the relative displacements between the tool and workpiece are added to the nominal cycloidal tool path ( $x$ and $y$-direction components of the tooth motion). The final tool path is used to calculate the SLE by isolating the machined workpiece surface from the entire tool path using a trimming algorithm. The SLE prediction steps are summarized here:

- describe the $\mathrm{x}$ and $\mathrm{y}$-direction cutting force components in the in time domain, $F_{x}(t)$ and $F_{y}(t)$, using the cutting conditions

- calculate the discrete Fourier transforms to obtain the cutting force components in the frequency domain, $F_{x}(\omega)$ and $F_{y}(\omega)$

- sum the tool-holder-spindle-machine FRF (i.e., the tool point FRF) and the workpiece FRF in both the $x$ and $y$-directions on a frequency-by-frequency basis:

$$
F R F_{x-\text { total }}(\omega)=F R F_{x-\text { tool }}(\omega)+F R F_{x-\text { workpiece }}(\omega)
$$




$$
F R F_{y-\text { total }}(\omega)=F R F_{y-\text { tool }}(\omega)+F R F_{y-\text { workpiece }}(\omega)
$$

- compute the frequency domain $x$ and $y$-direction displacements using $X_{\text {total }}(\omega)=F R F_{x-\text { total }}(\omega) \cdot F_{x}(\omega)$ and $Y_{\text {total }}(\omega)=F R F_{y-t o t a l}(\omega) \cdot F_{y}(\omega)$

- calculate the inverse Fourier transform of $X_{\text {total }}(\omega)$ and $Y_{\text {total }}(\omega)$ to obtain $x_{\text {total }}(t)$ and $y_{\text {total }}(t)$ in the time domain

- define the nominal cycloidal tool path and add the $\mathrm{x}$ and $\mathrm{y}$-direction components to $x_{\text {total }}(t)$ and $y_{\text {total }}(t)$

- isolate the machined surface from entire final tool path using a trimming algorithm

- predict the SLE using the machined surface geometry.

The nominal tool path $\mathrm{x}$ and y-coordinates, Xnom Eq. 10, where $r$ is the cutter radius, $\phi_{j}$ is the tooth angle, $j$ is the tooth number, $d f=\frac{N_{t} f_{t}}{S R}$ is the incremental feed during each time step, $d t=\frac{60}{S R \cdot \Omega}(\mathrm{sec}) . S R$ is the number of steps per cutter revolution and $\Omega$ is the spindle speed in rpm.

$$
\begin{aligned}
& \text { Xnom }_{j}=r \sin \phi_{j}+d f \\
& \text { Ynom }_{j}=r \cos \phi_{j}
\end{aligned}
$$

The coordinates of the corresponding tooth are calculated by adding the $\mathrm{x}$ and $\mathrm{y}$-direction displacements to the nominal coordinates:

$$
\begin{aligned}
& X_{j}=\text { Xnom }_{j}+x_{\text {total }} \\
& Y_{j}=\text { Ynom }_{j}+y_{\text {total }}
\end{aligned}
$$

Error! Reference source not found. displays an example final tool path ( $X_{j}$ versus $Y_{j}$ plot) which includes both the tool and workpiece deflections. From this figure, the machined surface geometry is isolated using a trimming algorithm (heavy solid line). The SLE is then computed using the mean of this vector of points and the tool radius. Specifically, $S L E=r-\bar{Y}_{j}$ for up milling and $S L E=-r-\bar{Y}_{j}$ for down milling [9]. Note that $+r$ is the intended location of the machined surface for up milling and $-r$ for down milling. 


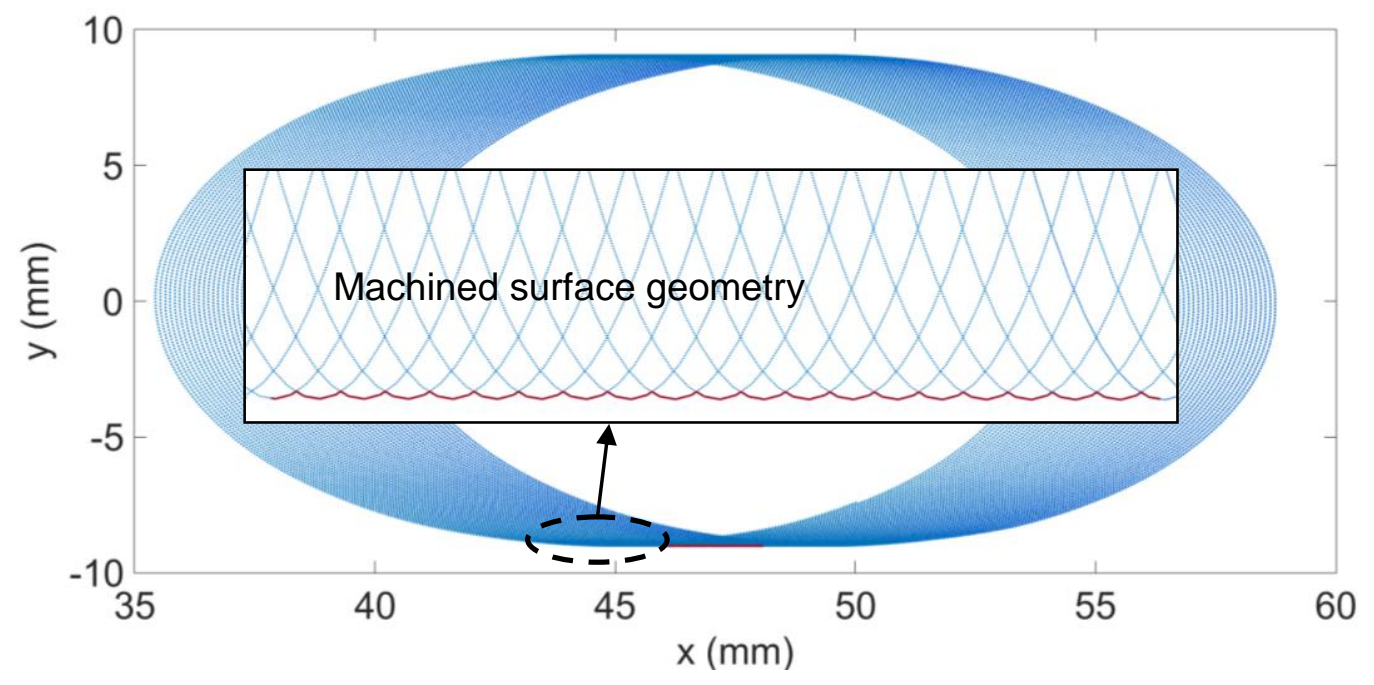

Figure 4. Tool path and the machined surface geometry (heavy solid line).

\section{Experimental setup}

In order to experimentally validate the frequency domain surface location error predictions, a flexure stage with tunable dynamics was designed and constructed. The flexure stage was composed of two parallelogram, leaf type flexures in an orthogonal, nested orientation; see Error! Reference source not found.. The workpiece was mounted on the upper platen which has flexibility in both the $x$ and $y$-directions. By selecting the leaf flexure's geometry (i.e., length, width, and thickness) and the mass of the upper and lower platens, the stiffness and natural frequency in both directions can be selected to meet experimental requirements. In the configuration shown in Error! Reference source not found., the geometry of the flexures in the $x$ and $y$-directions are identical. However, different flexure geometries for each direction may be selected so that the dynamic response of the validation platform varies by direction. This design feature enables milling experiments to be conducted on a two DOF system where one direction is significantly more flexible than the other, for example. 

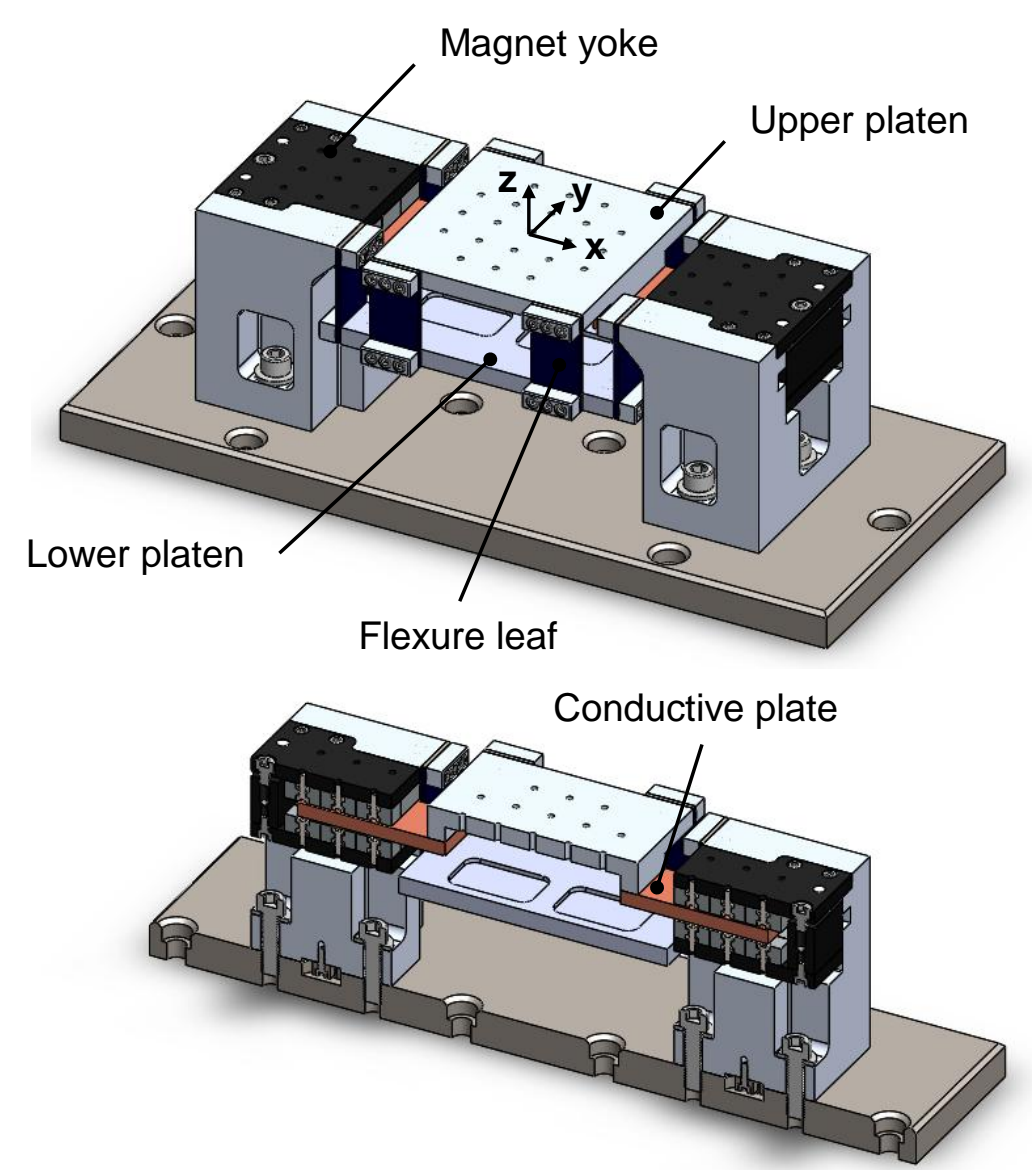

Figure 5. Assembly view (top) and section view (bottom) of the two DOF flexure stage.

In addition to tunable stiffness and natural frequency, the validation platform incorporates a pair of eddy current dampers to provide user-selected viscous damping. The damping force provided by the eddy current dampers can be predicted analytically, where the damping force is a function of the magnetic field strength. By varying the gap between the opposing faces of the magnet yoke assembly, the magnetic field strength and, therefore, the viscous damping forces are varied. The damping force acts on a copper conductor which is rigidly fixed to the upper platen; see Error! Reference source not found.. By virtue of the magnetic field orientation and motion of the upper platen, the viscous damping force acts in both the $x$ and $y$ directions. 


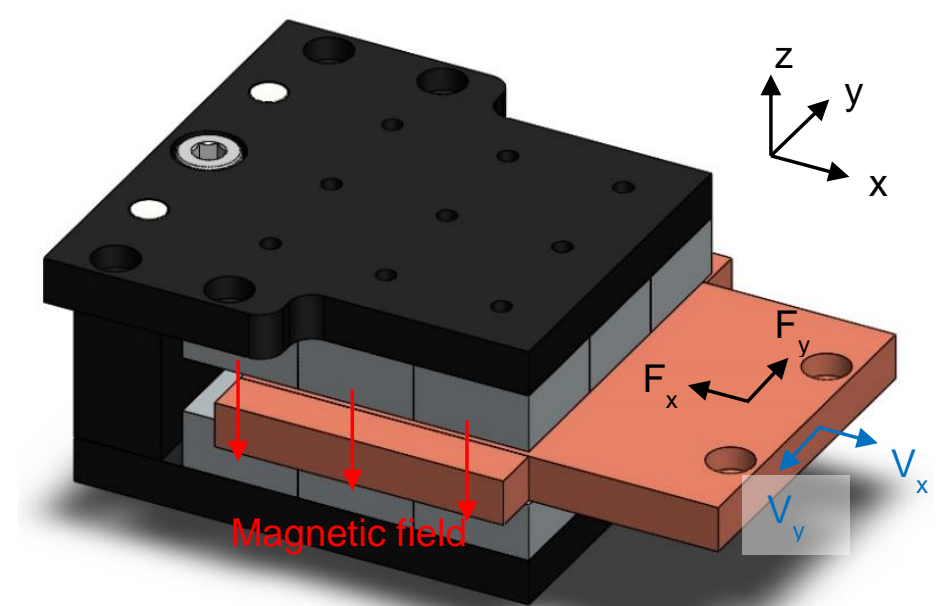

Figure 6. Solid model of eddy current damper including magnet yoke and conductive plate.

The upper platen, lower platen, and frame are composed of 6061-T6 aluminum and the base plate is composed of 1018 ground steel to provide a flat mounting surface for the flexure stage. Other materials include zinc-coated, alloy steel threaded fasteners and superconductive 101 copper for the eddy current damper. The magnet yoke assembly, shown in Error! Reference source not found., houses a pair of opposing, three-by-three arrays of Neodymium Iron Boron (NdFeB) magnets. By selecting a ferromagnetic material (i.e., mild steel) for the yoke assembly, a magnetic circuit is formed and the magnetic flux lines are directed in the gap between the magnet arrays. In this manner, the strength of the magnetic field is enhanced. Additionally, the magnetic field strength is adjustable by varying the gap between the magnet arrays. The mechanism for adjusting the gap width, shown in Error! Reference source not found., is conceptually similar to the vise stop which is commonly found in machine shops for repeatable workpiece positioning. The upper plate of the yoke assembly, which is rigidly fixed to the supporting structure of the flexure stage, houses two 8 $\mathrm{mm}$ dowel pins which are fixed in place by an interference fit. These dowel pins mate with the lower plate of the yoke assembly via a sliding fit and a series of Belleville washers provides a spring force which puts tension on the adjustment screw. The adjustment screw is accessible when the flexure stage is fully assembled, which facilitates convenient variation of the viscous damping force. 


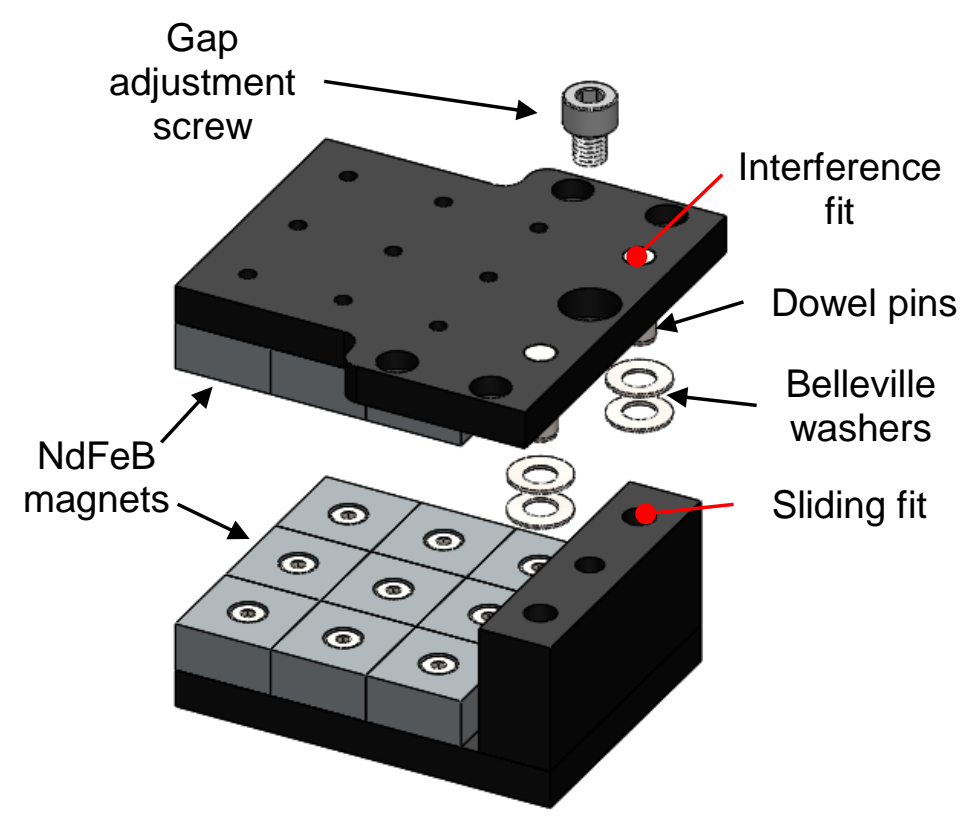

Figure 7. Exploded view of the magnet yoke assembly detailing the gap adjustment mechanism.

A thorough treatment of flexure design analysis is given by Smith [26]. For brevity, a complete derivation of the relevant design equations is omitted from this paper. However, a summary is provided. The stiffness of a parallelogram, leaf type flexure, $k$, where the force is applied at one-half the length of the leaf flexure is given by:

$$
k=2 E w\left(\frac{t}{l}\right)^{3}
$$

where $E$ is the elastic modulus of the flexure material and $w, t$, and $l$ are the flexure width, thickness, and length, respectively. The flexure stage was designed to have a variable stiffness depending on the leaf geometry. Two embodiments of the flexure stage stiffness, and corresponding leaf flexure geometry, are provided in

Table 1. These examples consider a total of four leaf flexures composed of hardened spring steel. In this case, the stiffness is tuned by varying the length of the flexure, but in principle the stiffness may be altered by varying any of the parameters in Eq. 12 .

Table 1. Example stiffness calculation for flexure stage considering 4 leaf-type flexures composed of spring steel.

Flexure geometry 


\begin{tabular}{|ccc|cc|}
\hline Length & Width & Thickness & Elastic modulus & Stiffness \\
\hline \hline $45 \mathrm{~mm}$ & $35 \mathrm{~mm}$ & $3.175 \mathrm{~mm}$ & $200 \mathrm{GPa}$ & $9.83 \times 10^{6} \mathrm{~N} / \mathrm{m}$ \\
$95 \mathrm{~mm}$ & $35 \mathrm{~mm}$ & $3.175 \mathrm{~mm}$ & $200 \mathrm{GPa}$ & $1.04 \times 10^{6} \mathrm{~N} / \mathrm{m}$ \\
\hline
\end{tabular}

The equivalent mass, $m_{e q}$, and undamped natural frequency, $\omega_{n}(\mathrm{rad} / \mathrm{s})$, of the flexure stage are given as:

$$
\begin{gathered}
m_{e q}=m_{p}+\frac{26}{35} m_{l} \\
\omega_{n}=\sqrt{\frac{k}{m_{e q}}}
\end{gathered}
$$

where $m_{p}$ is the total mass of the moving platen, leaf clamps, copper conductors, and fasteners and $m_{l}$ is the mass of the leaf flexures. Because the two, orthogonal DOFs are in a stacked (i.e., nested) arrangement, the equivalent masses (i.e., moving masses) are not the same. When the x-direction, defined in Error! Reference source not found., is set in motion, there is a larger moving mass. Therefore, for a fixed value of stiffness, the natural frequencies of the $x$ and $y$-direction vibrations are different. For the high stiffness arrangement given in

Table 1, the equivalent masses and natural frequencies for the two DOFs have been calculated and the results are summarized in Table 2. It is noteworthy that the x-direction, which has a higher equivalent mass, has a lower natural frequency. If equivalent natural frequencies in the $\mathrm{x}$ and $\mathrm{y}$-directions are desired, the mass and stiffness can be tuned accordingly.

Table 2. Equivalent mass and undamped natural frequency in the $x$ and $y$-directions for the high stiffness arrangement.

\begin{tabular}{ccccc}
\hline \multicolumn{5}{c}{ x-direction } \\
\hline$m_{p}$ & $m_{l}$ & $m_{e q}$ & $k$ & $f_{n}$ \\
\hline \hline $3.16 \mathrm{~kg}$ & $0.23 \mathrm{~kg}$ & $3.33 \mathrm{~kg}$ & $9.83 \times 10^{6} \mathrm{~N} / \mathrm{m}$ & $273 \mathrm{~Hz}$ \\
\hline & & y-direction & \\
\hline$m_{p}$ & $m_{l}$ & $m_{e q}$ & $k$ & $f_{n}$ \\
\hline \hline $2.52 \mathrm{~kg}$ & $0.23 \mathrm{~kg}$ & $2.69 \mathrm{~kg}$ & $9.83 \times 10^{6} \mathrm{~N} / \mathrm{m}$ & $304 \mathrm{~Hz}$ \\
\hline
\end{tabular}


The velocity-dependent viscous damping force is generated by an eddy current damper and can be calculated analytically. Error! Reference source not found. illustrates the motion (denoted by the velocity components $V_{x}$ and $V_{y}$ ) of a nonmagnetic conductor, which is fixed to the upper platen, relative to the magnet arrays housed within the steel yokes. Because the relative motion is orthogonal to the magnetic flux direction, eddy currents are generated within the conductor. The eddy current density, $\vec{J}$, depends upon the conductivity, $\sigma$, and the cross product of the velocity, $\vec{v}$, and magnetic field, $\vec{B}$ according to Eq. 15 . The viscous damping force is then calculated as the volume integral of the cross product of the eddy current density and magnetic field; see Eq. 16. The resulting viscous damping force acts in the direction opposite the velocity.

$$
\begin{gathered}
\vec{J}=\sigma(\vec{v} \times \vec{B}) \\
\vec{F}=\int_{V}(\vec{J} \times \vec{B}) d V
\end{gathered}
$$

The magnitude of the viscous damping force is given by:

$$
F=\left[\sigma \delta B^{2} S\left(\alpha_{1}+\alpha_{2}\right)\right] v=c v
$$

where $\delta$ is the thickness of the conductor, $B$ is the magnetic field strength, $S$ is the area of the magnet array, $\alpha_{1}$ incorporates surface charge effects, $\alpha_{2}$ incorporates end charge effects from the finite width conductor, and $v$ is the velocity magnitude [27]. This viscous damping coefficient, $c$, enables model-based damping prediction and selection for milling operations. The design parameters for a single eddy current damper (i.e., the proposed design has two) are listed in Table 3.

Table 3. Eddy current damper design parameters.

\begin{tabular}{|c|c|}
\hline Parameter & Value \\
\hline$\sigma$ & $5.96 \times 10^{7} \mathrm{~A} / \mathrm{V}-\mathrm{m}$ \\
\hline$\delta$ & $10 \mathrm{~mm}$ \\
\hline$B$ & 3400 Gauss $(0.34 \mathrm{~T})$ \\
\hline$S$ & $5.8 \times 10^{-3} \mathrm{~m}^{2}$ \\
\hline
\end{tabular}




\begin{tabular}{|c|c|}
\hline$\alpha_{1}{ }^{*}$ & 0.500 \\
\hline$\alpha_{2, x}{ }^{*}$ & -0.234 \\
\hline$\alpha_{2, y}{ }^{*}$ & -0.290 \\
\hline
\end{tabular}

It is important to note that the magnetic field strength is not constant throughout the magnet array gap. Therefore, the viscous damping coefficient depends on the average magnetic field strength within the copper conductor. With a nominal magnet array gap of $12 \mathrm{~mm}$, the average magnetic field strength was measured to be $0.34 \mathrm{~T}$. For the parameters listed in Table 3 the calculated value of the viscous damping coefficients for the $x$ and $y$-directions are $105(\mathrm{~N} \cdot \mathrm{s}) / \mathrm{m}$ and $83(\mathrm{~N} \cdot \mathrm{s}) / \mathrm{m}$, respectively. For the pair of eddy current dampers, arranged symmetrically about the upper platen, the total damping coefficients for a nominal magnet array gap of $12 \mathrm{~mm}$ in the $\mathrm{x}$ and y-directions are $210(\mathrm{~N} \cdot \mathrm{s}) / \mathrm{m}$ and $166(\mathrm{~N} \cdot \mathrm{s}) / \mathrm{m}$, respectively.

The corresponding dimensionless damping ratios, $\zeta$, in the $\mathrm{x}$ and $y$-directions, calculated using Eq. 18, are 0.0184 (1.84\%) and 0.0162 (1.62\%), respectively. Because the damping ratio depends on both stiffness and effective mass (both of which are adjustable), the dimensionless damping ratio can be modified as needed for milling experiments.

$$
\zeta=\frac{c}{2 \sqrt{k m_{e q}}}
$$

To illustrate the effect of the eddy current damper, the measured $x$-direction FRF for several values of magnet array gap are displayed in

. Measured and predicted viscous damping ratios are given in Table for representative values of the magnet array gap. It is observed that the damping is increased by approximately an order of magnitude through incorporation of the eddy current damper. 

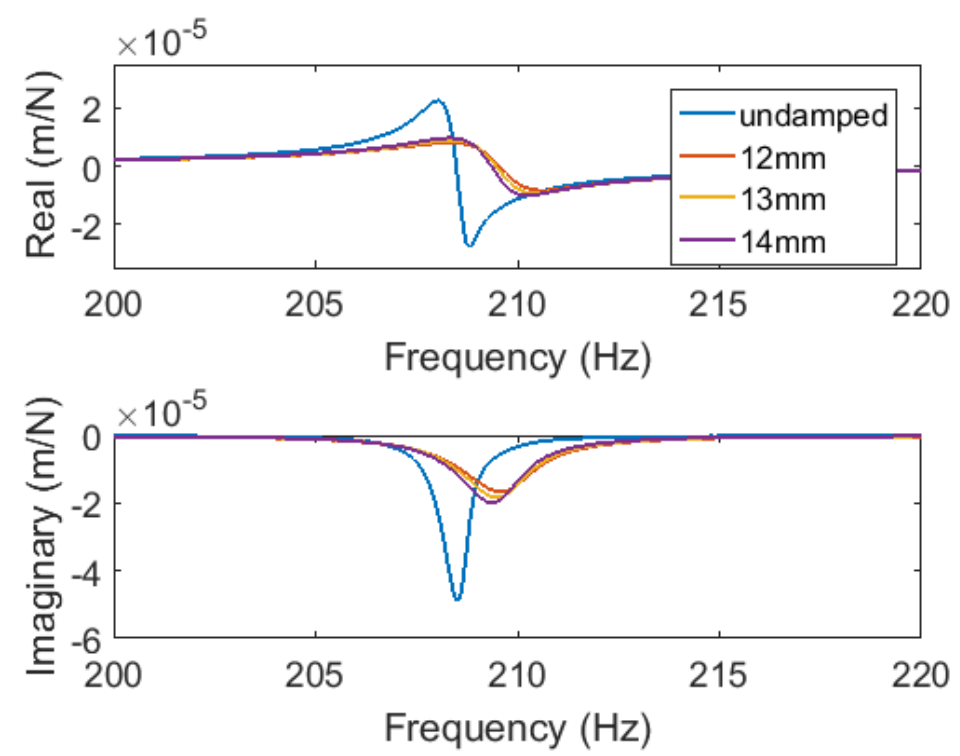

Figure 8. Measured flexure stage FRF showing the effect of viscous damping by varying the magnet array gap.

Table 4. Measured and predicted viscous damping ratios.

\begin{tabular}{|c|c|c|c|}
\hline Nominal magnet array gap (mm) & & Predicted & Measured \\
\hline \multirow{2}{*}{12} & $\zeta_{x}(\%)$ & 1.84 & 1.52 \\
\hline & $\zeta_{\mathrm{y}}(\%)$ & 1.62 & 1.51 \\
\hline \multirow{2}{*}{13} & $\zeta_{x}(\%)$ & 1.78 & 1.28 \\
\hline & $\zeta_{y}(\%)$ & 1.56 & 1.20 \\
\hline \multirow{2}{*}{14} & $\zeta_{x}(\%)$ & 1.71 & 1.14 \\
\hline & $\zeta_{y}(\%)$ & 1.50 & 1.04 \\
\hline \multirow{2}{*}{ Undamped } & $\zeta_{x}(\%)$ & - & 0.18 \\
\hline & $\zeta_{y}(\%)$ & - & 0.14 \\
\hline
\end{tabular}

\section{Surface location error prediction and experimental results}

Down milling surface location error predictions were completed at spindle speeds ranging from $13350 \mathrm{rpm}$ to $14650 \mathrm{rpm}$ in $10 \mathrm{rpm}$ increments with: $f_{t}=0.1 \mathrm{~mm} / \mathrm{tooth}, \gamma=0^{\circ}, N_{t}=1$, $b=6 \mathrm{~mm}$, and $a=1 \mathrm{~mm}$. The spindle speed range was determined based on the process stability predicted using the Fourier series approach [3]. Only stable cuts were analyzed 
because the frequency domain approach is based on forced vibration. The tool-holderspindle-machine FRF (at the tool point) and workpiece FRF represented by the two DOF flexure were measured by impact testing in both the $x$ and $y$-directions using the experimental setup shown in Error! Reference source not found.. The measured FRFs for the tool point and flexure in both directions were added to find the total compliance (as described in Section 4). The summed FRFs are displayed in Error! Reference source not found..

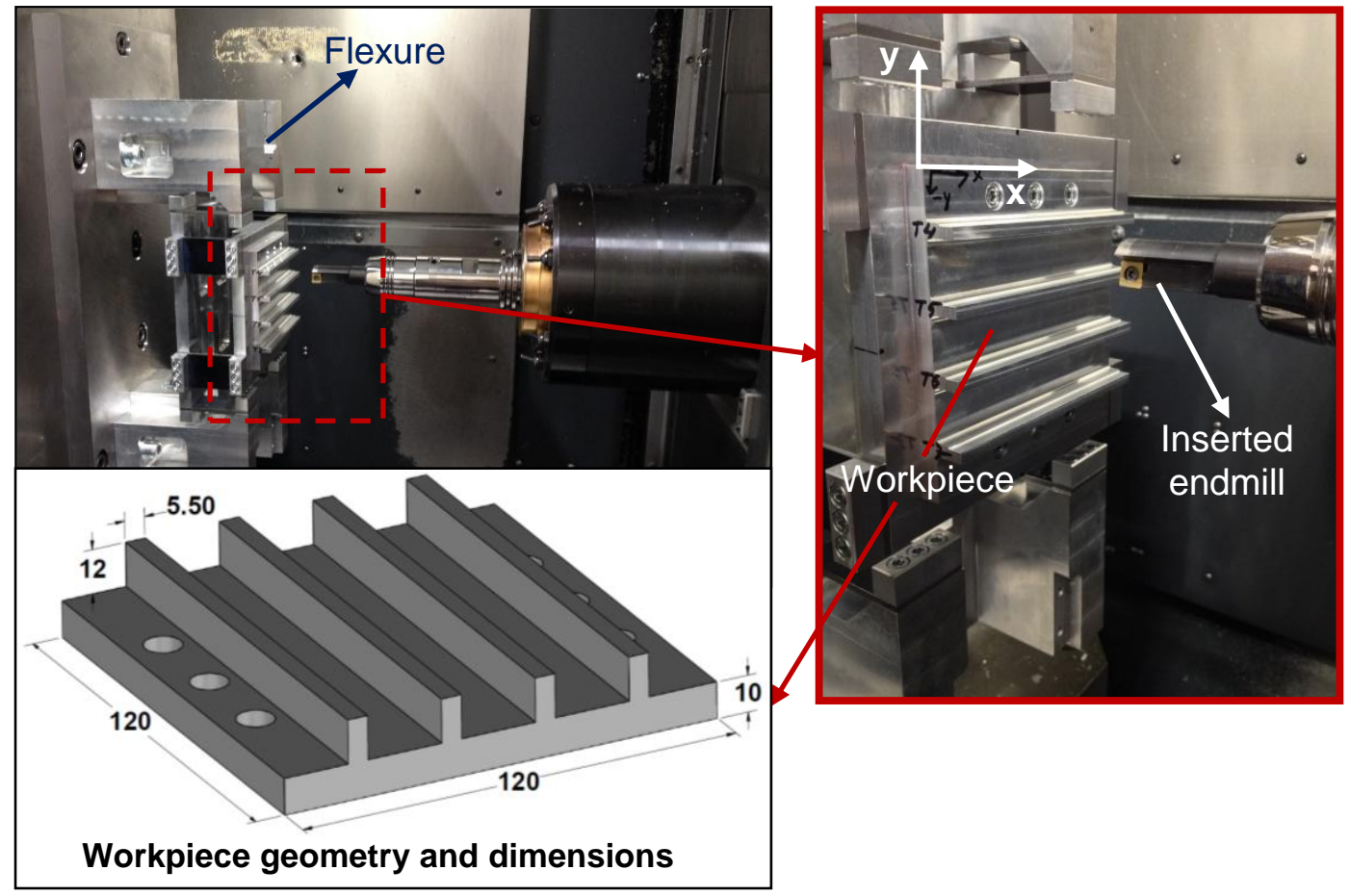

Figure 9. Surface location error experimental setup (dimensions are in $\mathrm{mm}$ ). The FRF measurement locations for the flexure were at the middle edges of the workpiece. 

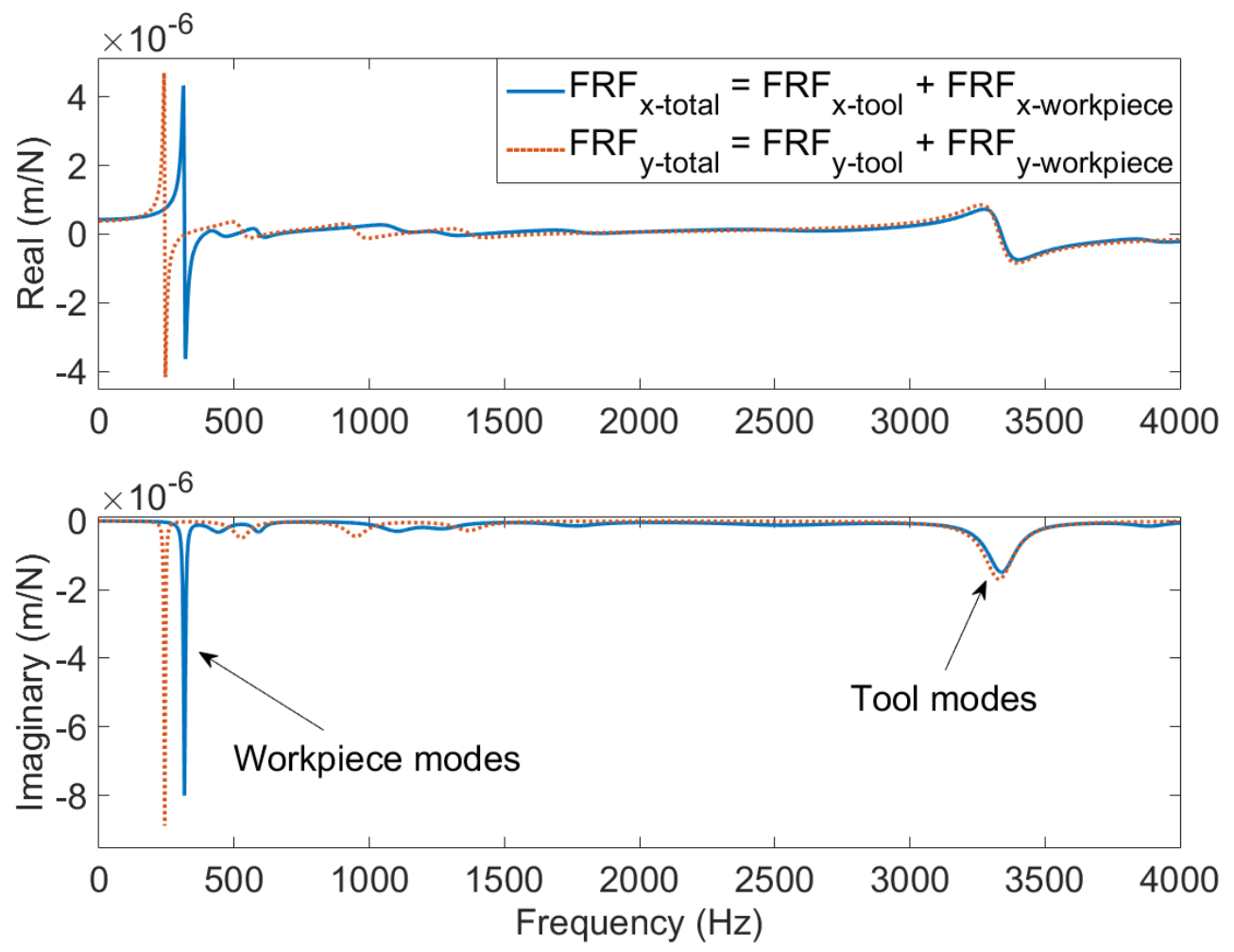

Figure 10. Summed FRFs for the $x$ and $y$-directions. (Top) real part. (Bottom) imaginary part.

Table 5. Modal parameters for flexure and tool.

\begin{tabular}{|c|c|c|c|c|}
\hline Flexure & $\boldsymbol{k}_{\boldsymbol{q}}(\mathbf{N} / \mathbf{m})$ & $\boldsymbol{m}_{\boldsymbol{q}} \mathbf{( k g )}$ & $\boldsymbol{\zeta}_{\boldsymbol{q}}$ & $\boldsymbol{f}_{\boldsymbol{n}}(\mathbf{H z})$ \\
\hline x-direction & $5.15 \times 10^{6}$ & 1.30 & $1.22 \%$ & 316.3 \\
\hline y-direction & $5.38 \times 10^{6}$ & 2.30 & $1.05 \%$ & 243.4 \\
\hline Tool & $\boldsymbol{k}_{\boldsymbol{q}}(\mathbf{N} / \mathbf{m})$ & $\boldsymbol{m}_{\boldsymbol{q}} \mathbf{( k g )}$ & $\boldsymbol{\zeta}_{\boldsymbol{q}}$ & $\boldsymbol{f}_{\boldsymbol{n}}(\mathbf{H z})$ \\
\hline x-direction & $1.76 \times 10^{7}$ & 0.040 & $1.91 \%$ & 3340 \\
\hline y-direction & $1.49 \times 10^{7}$ & 0.034 & $1.97 \%$ & 3331 \\
\hline
\end{tabular}

A modal fit was performed using the peak-picking method [24]. The results are provided in Table 5. The reader may note that the flexure FRFs measurements were performed with the workpiece attached so that its mass was included in the final response. The corresponding stability map is displayed in Error! Reference source not found.; it was generated using the summed FRFs for a $1 \mathrm{~mm}$ radial depth down milling cut. The 6061-T6 aluminum workpiece cutting force coefficients were: $k_{t}=852.6 \times 10^{6} \mathrm{~N} / \mathrm{m}^{2}, k_{t e}=18.05 \times 10^{3} \mathrm{~N} / \mathrm{m}$, $k_{n}=322.17 \times 10^{6} \mathrm{~N} / \mathrm{m}^{2}$, and $k_{n e}=22.04 \times 10^{3} \quad \mathrm{~N} / \mathrm{m}$. These coefficients were identified 
experimentally for the selected tool-workpiece pair using the techniques describes in [9] and [25].

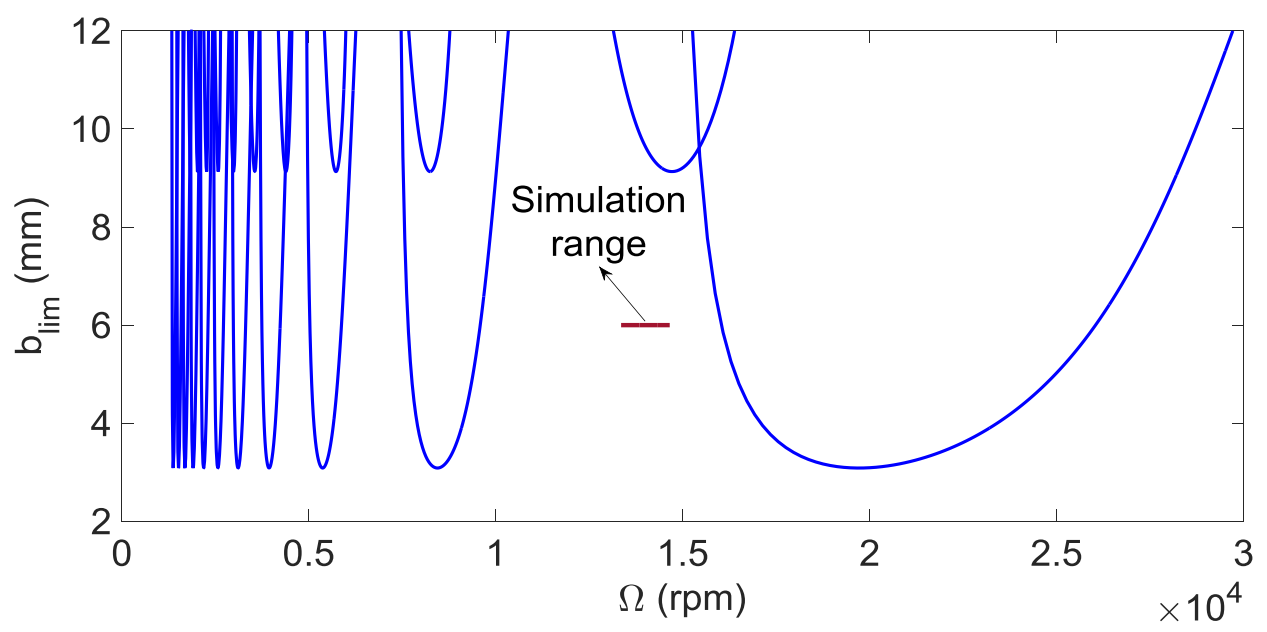

Figure 11. Stability map including both tool and workpiece flexibility. The spindle speed, $\Omega$, is plotted versus the limiting axial depth of cut for stable performance, $b_{\text {lim. }}$.

For verification of the SLE predictions, seven test points were selected within the stable spindle speed range identified in Fig. 11. The other cutting conditions were kept constant while the spindle speed alone was varied $(6 \mathrm{~mm}$ axial depth of cut, $1 \mathrm{~mm}$ radial depth of cut, and $0.1 \mathrm{~mm} /$ tooth feed). The spindle speed defined the excitation frequency (tooth passing frequency) which modifies the forced vibration level and, therefore, the SLE. The workpiece was mounted on the two DOF flexure as shown in Error! Reference source not found.. Each workpiece had four ribs so two total workpieces were used. In the experiments, a single tooth square inserted endmill (Kennametal model KICR-0.73-SD3-033.3C) with a diameter of $18.46 \mathrm{~mm}$ and a $15^{\circ}$ relief angle (SDCW322 KC725M) was used.

Prior to performing the SLE test cuts on the workpiece, a finish pass was completed on each side of ribs at an axial depth of $10.16 \mathrm{~mm}$ while test workpiece was mounted on the two DOF flexure. This ensured that the workpiece was aligned with the milling machine coordinate frame. After the finish passes, an SLE test cut was completed on each rib at the predefined spindle speeds. The SLE was measured using a touch-probe coordinate measuring machine (CMM). The measurement procedure is shown in Error! Reference source not found.. Three scans were performed on each rib: a reference scan $3 \mathrm{~mm}$ from the rib top on the side without an SLE cut (right side of the workpiece for the right inset in Fig. 12); a reference scan $8 \mathrm{~mm}$ from the rib top on the SLE side, but below the cut; and a measurement scan $3 \mathrm{~mm}$ from the rib top on the SLE cut surface. 


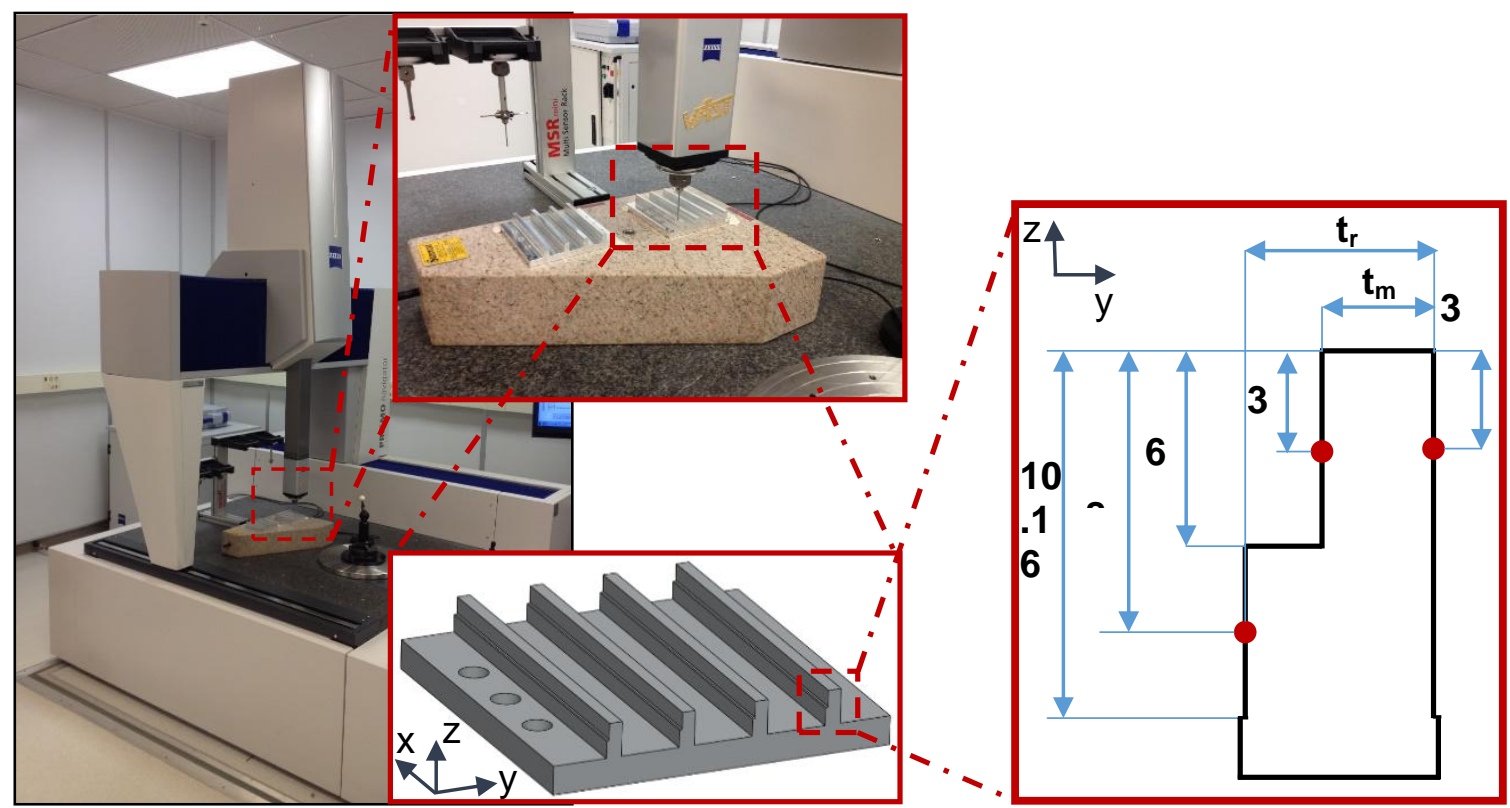

Figure 12. SLE measurement procedure.

Using the three scans, two thickness values were calculated, $t_{r}$ and $t_{m}$, as shown in Fig. 12 . The reference thickness for the rib is $t_{r}$, calculated from the difference between the left scan at $8 \mathrm{~mm}$ and the right scan at $3 \mathrm{~mm}$, and the measured thickness after the SLE test cut is $t_{\mathrm{m}}$, calculated from the difference between the left scan at $3 \mathrm{~mm}$ and the right scan at $3 \mathrm{~mm}$. The difference between these two is ideally the radial depth of cut, a. The SLE was therefore calculated using Eq. 19. Note that the points for each scan were fit by spline interpolation prior to calculating the difference.

$$
S L E=\left(t_{r}-t_{m}\right)-a
$$

As an example, the three scanned rib profiles and corresponding SLE values for the test carried out at $14310 \mathrm{rpm}$ are provided in Error! Reference source not found.. Each scan was started and stopped at the same y location at a single $z$ height. 


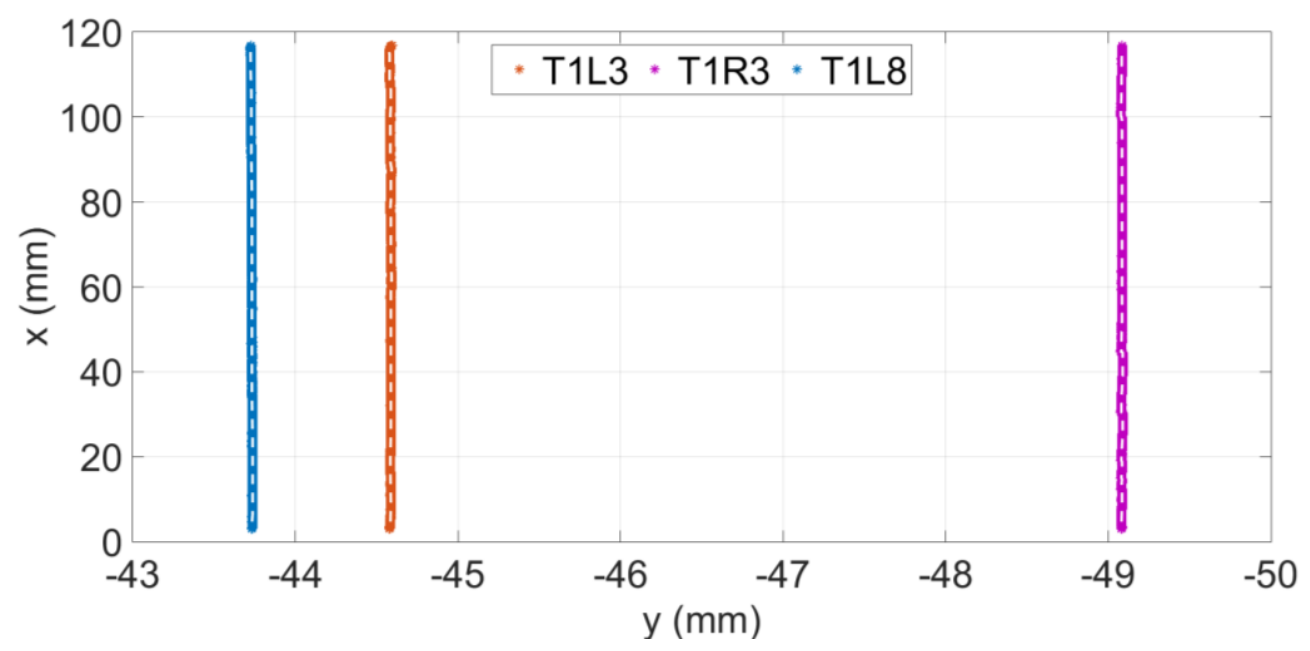

a)

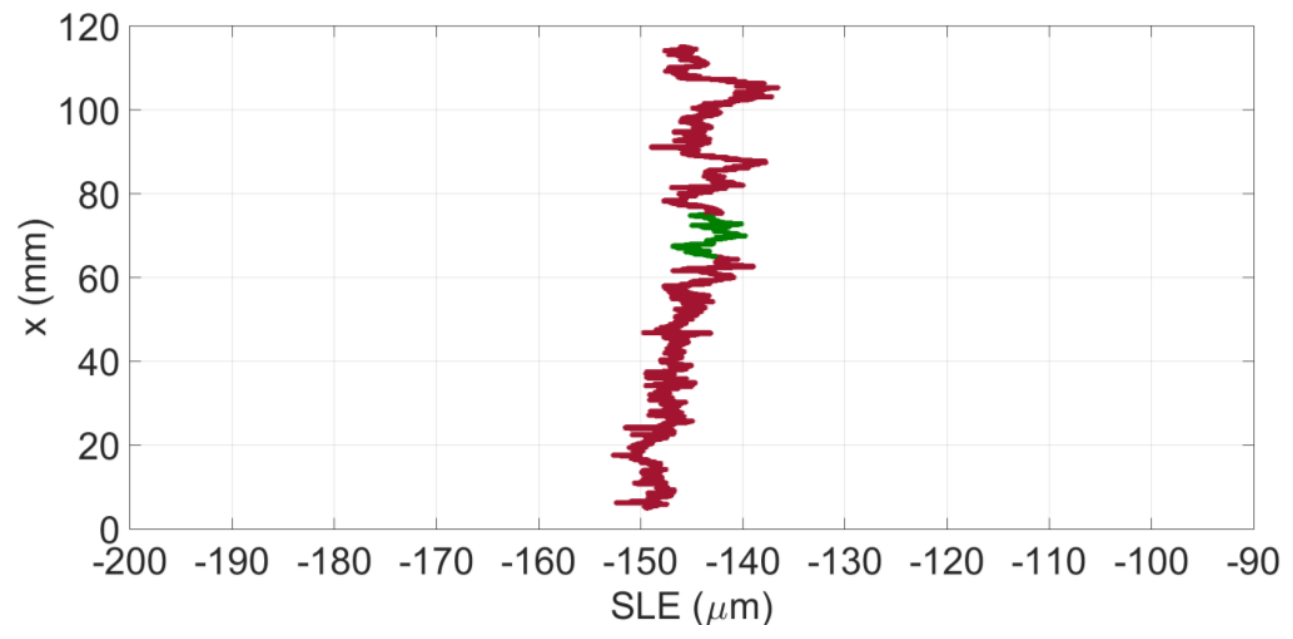

b)

Figure 13. a) CMM points for three scans from Fig. 12. T1R3 is a reference scan $3 \mathrm{~mm}$ from the rib top on the right side without an SLE cut; T1R8 is a reference scan $8 \mathrm{~mm}$ from the rib top on the left side; and T1L3 is a measurement scan $3 \mathrm{~mm}$ from the rib top on the left side.

b) SLE calculated using Eq. 19.

To avoid the cut entry and exit transients, the SLE was calculated using only the steadystate (i.e., central) region of the data shown in Fig. 13b (between $60 \mathrm{~mm}$ and $80 \mathrm{~mm}$ ). The same steady-state region was used for all experiments. The final SLE is reported as the average value from this region.

Predictions were made using time domain simulation and the new closed-form frequency domain solution and the results were compared to experiment; see Fig. 14. The negative SLE values indicate an undercut surface, which means that less material is removed than commanded for down milling. It is observed that the time domain [9] and frequency domain 
solutions closely agree. The experimental results verify the dramatic change in SLE with spindle speed (>200 $\mu \mathrm{m}$ over a spindle speed range of approximately $200 \mathrm{rpm}$ ).

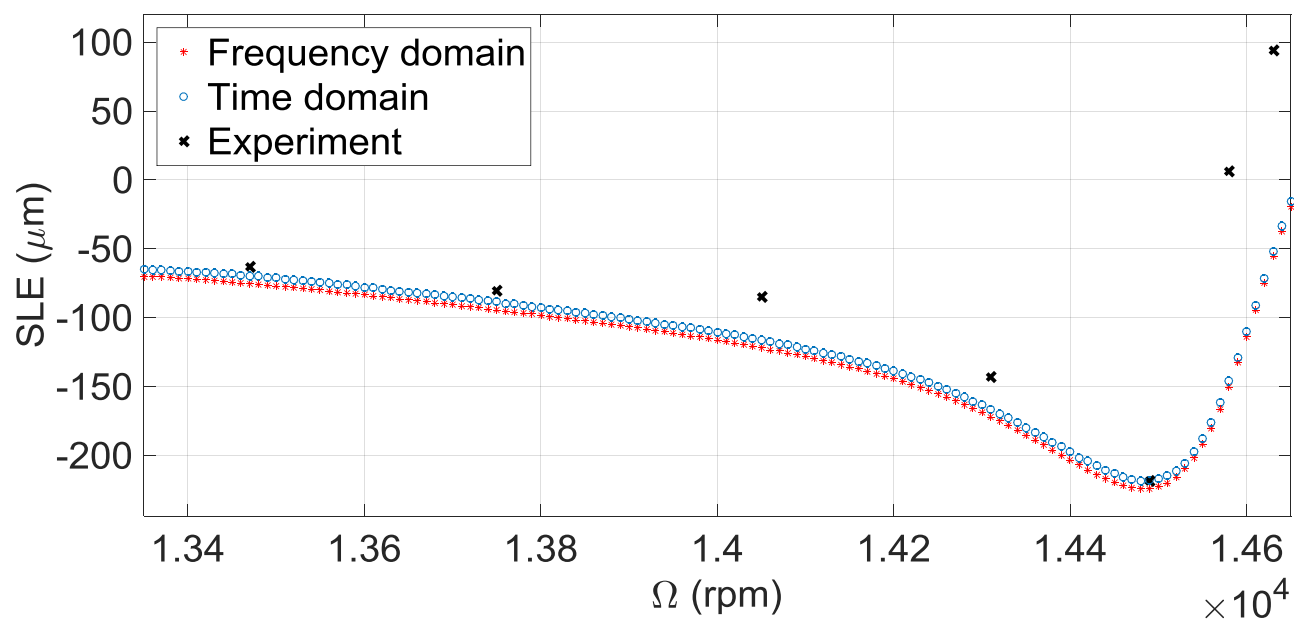

Figure 14. Comparison between closed-form frequency domain, time domain, and experimental results.

\section{Conclusions}

This paper presented a closed-form frequency domain solution to predict surface location errors considering both the tool and workpiece flexibility in two directions. The calculated tool and workpiece deflections were added to the nominal cycloidal tool path and the machined surface profile was extracted from the sum. A comparison between the frequency domain solution, time domain simulation, and experimental results were provided for a range of spindle speeds. Good agreement was observed and the strong dependence of surface location error on spindle speed was demonstrated. For the experiments, a two DOF flexure, which represented the workpiece flexibility, was designed and constructed. The new frequency domain surface location error solution offers an analytical alternative to time domain simulation with less computation time. By combining the surface location error prediction with stability analysis, optimized cutting parameters can be selected at the process planning stage.

\section{Acknowledgements}

The authors gratefully acknowledge the Scientific and Technological Research Council of Turkey (TUBITAK) 2214/A International Doctoral Research Fellowship Programme for a research scholarship to the author, Kadir Kiran, in order to perform research at UNC Charlotte. The authors also acknowledge partial financial support from the National Science Foundation under Grant No. CMMI-1561221. 


\section{References}

1. Tlusty J, Zaton W, Ismail F. Stability lobes in milling. Annals of the CIRP 1983;32(1):309-313.

2. Smith S, Tlusty J, An overview of modeling and simulation of the milling process, Journal of Engineering for Industry 1991;113 (2):169-175.

3. Altintas $Y$, Budak E. Analytical prediction of stability lobes in milling. Annals of the CIRP 1995;44(1):357-362.

4. Tlusty J. Manufacturing Processes and Equipment. Upper Saddle River, NJ: PrenticeHall, Inc.; 2000.

5. Altintas Y. Manufacturing Automation: Metal Cutting Mechanics, Machine Tool Vibrations, and CNC Design. Cambridge, UK: Cambridge University Press; 2000.

6. Altintas $\mathrm{Y}$, Weck M. Chatter stability of metal cutting and grinding. Annals of the CIRP 2004;53(2):619-642.

7. Insperger T, Mann BP, Stepan G, Bayly PV. Stability of up-milling and down-milling, part 1: Alternative analytical methods. International Journal of Machine Tools and Manufacture 2003;43:25-34.

8. Eksioglu C, Kilic ZM, Altintas Y. Discrete-time prediction of chatter stability, cutting forces, and surface location errors in flexible milling systems. Transactions of ASME Journal of Manufacturing Science and Engineering 2012;134(6): 061006.

9. Schmitz T, Smith KS. Machining Dynamics: Frequency Response to Improved Productivity. New York, NY: Springer; 2009.

10. Schmitz T, Mann B. Closed form solutions for surface location error in milling. International Journal of Machine Tools and Manufacture 2006;46: 1369-1377.

11. Schmitz T, Ziegert J. Examination of surface location error due to phasing of cutter vibrations. Precision Engineering 1999;23 (1):51-62.

12. Shirase K, Altintas $\mathrm{Y}$. Cutting force and dimensional surface error generation in peripheral milling with variable pitch helical end mills. International Journal of Machine Tools and Manufacture 1996;36(5): 567-584.

13. Mann BP, Edes BT, Easley SJ, Young KA, Ma K. Chatter vibration and surface location error prediction for helical end mills. International Journal of Machine Tools and Manufacture 2008;48:350-361.

14. Schmitz T, Couey J, Marsh Eric, Mauntler N, Hughes D. Runout effects in milling: Surface finish, surface location error, and stability. International Journal of Machine Tools and Manufacture 2007;47:841-851.

15. Zapata R, Schmitz T. A new "super diagram" for describing milling dynamics, Transactions of NAMRI/SME 2009;36: 245-252. 
16. Bachrathy D, Insperger T, Stépán G. Surface properties of the machined workpiece for helical mills. Machining Science and Technology 2009;13(2): 227-245.

17. Kiss AK, Bachrathy D, Stepan G. Cumulative surface location error for milling processes based on tool-tip frequency response function. Procedia CIRP 2016;46:323-326.

18. Insperger T, Gradišek J, Kalveram M, Stépán G, Winert K, Govekar E. Machine tool chatter and surface location error in milling processes. Transactions of ASME Journal of Manufacturing Science and Engineering 2006;128: 913-920.

19. Siebrecht T, Kersting P, Biermann D, Odendahl S, Bergmann J. Modeling of surface location errors in a multi-scale milling simulation system using a tool model based on triangle meshes. Procedia CIRP 2015;37: 188-192.

20. Wan M, Zhang WH, Qin GH, Wang ZP. Strategies for error prediction and error control in peripheral milling of thin-walled workpiece. International Journal of Machine Tools and Manufacture 2008;48: 1366-1374.

21. Desai KA, Rao PVM. On cutter deflection surface errors in peripheral milling. Journal of Materials Processing Technology 2012;212: 2443- 2454.

22. Aydın M, Uçar M, Cengiz A, Kurt M. Identification of static surface form errors from cutting force distribution in flat-end milling processes. Journal of the Brazilian Society of Mechanical Sciences and Engineering 2015;37: 1001-1013.

23. Wei ZC, Wang MJ, Cai YJ, Zhu JN, Wang L. Form error estimation in ball-end milling of sculptured surface with z-level contouring tool path. The International Journal of Advanced Manufacturing Technology 2013;65: 363-369.

24. Schmitz T, Smith KS. Mechanical Vibrations: Modeling and Measurement. New York, NY: Springer; 2012.

25. Rubeo MA, Schmitz T. Mechanistic force model coefficients: A comparison of linear regression and nonlinear optimization. Precision Engineering 2016;45: 311-321.

26. Smith S. Flexures: Elements of Elastic Mechanisms. London, UK: CRC Press; 2000.

27. Bae JS, Kwak MK, Inman DJ. Vibration suppression of a cantilever beam using eddy current damper. Journal of Sound and Vibration 2005; 284(3-5): 805-824. 